Bio - grafía. Escritos sobre la Biología y su Enseñanza. ISSN 2027-1034

Edición Extraordinaria. p.p. 601 - 609

Memorias del IX Encuentro Nacional de Experiencias en Enseñanza de la Biología y la Educación Ambiental. IV Congreso Nacional de Investigación en Enseñanza de la Biología.

\title{
INTERVENÇÃO EM ESPAÇO PÚBLICO COMO ESTRATÉGIA DE ENSINO: ANÁLISE A PARTIR DE UMA VERTENTE PEDAGÓGICA CRÍTICA DA EDUCAÇÃO AMBIENTAL
}

\author{
Everton Joventino da Silva ${ }^{1}$ \\ Maria Delourdes Maciel $^{2}$ \\ Rita de Cassia Frenedozo ${ }^{3}$ \\ Yonier Alexander Orozco Marín ${ }^{4}$
}

\section{RESUMEN}

Grandes metrópolis como San Pablo (Brasil) poseen espacios públicos como parques y jardines que en los barrios periféricos son escasamente utilizados por la población. Estos espacios poseen grande potencial para la discusión y construcción de acciones relacionadas con la educación ambiental. Sin embargo, es necesario comprender de que forma las actividades construidas en el ambiente escolar contribuyen para la formación de profesores, estudiantes y de la comunidad. En esta investigación se analizó por medio de análisis de contenido, una actividad de educación ambiental y sus relaciones con la corriente pedagógica critica de educación ambiental. Los resultados obtenidos indican que la actividad analizada y la corriente critica ofrecen posibilidades como la resolución de problemas a partir de tópicos generadores y algunas limitaciones como la dificultad de construir actividades de carácter interdisciplinar.

PALABRAS CLAVE: Educación ambiental; Espacios públicos; Corriente pedagógica critica.

\section{ABSTRACT}

Big Metropolis like the city of Sao Paulo (Brazil) have public spaces such as parks and gardens that in the suburbs become less used by the population. These places have a great potential for a discussion and construction of actions towards the Environmental Education, however, it is necessary to understand how activities built in the school environment contribute to teachers, students and community training. This research we are going to analyse through the Content of Analyses an activity of Environmental Education and its relations with a Critical Pedagogical Strand of Environmental Education. The results acquired show that the activity analysed and the Critical Strand have approaches like the resolutions of problems from themes created and limitations like the difficulty of building activities with interdisciplinary character.

\footnotetext{
1 evertonj007@hotmail.com

2 delourdes.maciel@gmail.com

3 ritafrenedozo@yahoo.com.br

4 apmusicomano@gmail.com

1,2,3 Universidade Cruzeiro do Sul, São Paulo, São Paulo Brasil

${ }^{4}$ Universidade Federal do Acre, Rio Branco, Acre, Brasil
} 
Bio - grafía. Escritos sobre la Biología y su Enseñanza. ISSN 2027-1034

Edición Extraordinaria. p.p. 601 - 609

Memorias del IX Encuentro Nacional de Experiencias en Enseñanza de la Biología y la Educación Ambiental. IV Congreso Nacional de Investigación en Enseñanza de la Biología.

KEY WORDS: Environmental Education, Public Spaces, Critical Pedagogical Strand.

\section{INTRODUÇÃO}

Nos grandes centros urbanos os espaços públicos como parques e praças são de grande importância para que a população além de ter contato com a natureza, possa também usufruir de uma opção de lazer. Bermudez e De Longhi (2006) destacam a importância destes espaços nos grandes centros urbanos, onde o contato com a biodiversidade em contextos naturais é escasso, aspecto que determina o conhecimento limitado sobre as espécies e ecossistemas regionais por parte de jovens e adultos.

Praças e jardins públicos em ambientes urbanos configuram-se verdadeiros "oásis" dentro dos bairros periféricos de grandes metrópoles como São Paulo, e possuem características singulares, dentre elas, as destacadas por Almeida, Bicudo e Borges (2004) como a manutenção do clima ameno, capacidade de dar condições de sobrevivência as inúmeras espécies de fauna e flora local e um componente importante do ecossistema urbano.

Destaca-se então a importância ecológica da criação e manutenção de mais espaços públicos como praça e jardins, na medida em que estes espaços contribuem para a manutenção da fauna e flora em ambientes urbanos.

Almeida, Bicudo e Borges (2004) como eficiente estratégia a ocupação de espaços públicos, de modo que possam relacioná-los a acontecimentos socioculturais e a utilização como espaços educativos que contribuíam para a de reflexão sobre aspectos históricos e ambientais das cidades.

Diante do relevante potencial de espaços públicos como as praças para a promoção da Educação Ambiental no contexto urbano, é necessário compreender de que forma práticas de ensino podem colaborar para a uma melhor utilização destes espaços. O ambiente escolar é um dos locais para que ocorra discussões no sentido de levantar problemas de diversas ordens, como os ambientes, bem como a construções de propostas e ações para minimizá-los ou resolvê-los.

Nesta pesquisa analisaremos as possibilidades e desafios de uma atividade de Educação Ambiental e suas relações com uma Vertente Pedagógica Crítica da Educação Ambiental, em participaram professores de ciências, biologia, história, português e educação física e estudantes do $9^{\circ}$ ano do Ensino Fundamental e $1^{\circ}$ ano do Ensino Médio de uma escola pública da periferia da cidade de São Paulo, Brasil. O objetivo desta pesquisa é identificar as relações entre uma proposta de uma atividade de Educação Ambiental com uma Vertente Crítica de Educação Ambiental.

\section{REFERENCIAL TEÓRICO}

No contexto brasileiro Silva (2007) destaca que a "Educação Ambiental tem suas raízes no movimento ambientalista que também pauta suas ações em diferentes concepções"(p.57). Carvalho (2002) salienta que a EA é marcada por disputas que envolvem diferentes ênfases e compreensões acerca da problemática ambiental, resultando em diversos conceitos, programas e analises pedagógicas de intervenção. 
Bio - grafía. Escritos sobre la Biología y su Enseñanza. ISSN 2027-1034

Edición Extraordinaria. p.p. 601 - 609

Memorias del IX Encuentro Nacional de Experiencias en Enseñanza de la Biología y la Educación Ambiental. IV Congreso Nacional de Investigación en Enseñanza de la Biología.

Diversas são as práticas associadas à EA que podem ser desenvolvidas por professores e estudantes no ambiente escolar, entretanto há de se considerar que para a análise destas práticas, devemos estar cientes de que, como destaca González Gaudiano (2007), na EA coexistem ênfases desde a conservação ecológica até as que articulam a problemática da deteriorização as condições culturais, econômicas e sociais.

Uma exemplificação acerca das diferentes concepções no campo da EA pode ser entendida por meio de trabalhos que buscavam categorizar a presença de vertentes da EA. Dentre diversos trabalhos destaca-se o da autora Silva (2007) destaca as seguintes tendências: Conservadora, Pragmática e Crítica. características:

A Educação Ambiental Conservadora caracteriza-se pelas seguintes

Quadro 1. Tendências da Educação Ambiental

\begin{tabular}{|c|l|}
\hline Tendência da EA & \multicolumn{1}{|c|}{ Características } \\
\hline Conservadora & $\begin{array}{l}\text { São apresentados os problemas ambientais mais aparentes, } \\
\text { desprezando-se as causas mais profundas. Ocorre uma relação } \\
\text { dicotômica entre o ser humano e o ambiente, sendo o primeiro } \\
\text { apresentado como destruidor. Praticamente não são abordadas } \\
\text { questões sociais e políticas. }\end{array}$ \\
\hline Pragmática & $\begin{array}{l}{[\ldots . .] \text { o foco na ação, na busca de soluçães para os problemas }} \\
\text { ambientais e na proposição de normas a serem seguidas. [...] } \\
\text { Busca mecanismos que compatibilizem desenvolvimento } \\
\text { econômico com manejo sustentável de recursos naturais } \\
\text { (desenvolvimento sustentável). A ênfase é na mudança de } \\
\text { comportamento individual por meio da quantidade de } \\
\text { informações e de normas ditadas por leis e por projetos } \\
\text { governamentais, que são apresentados como soluções prontas. }\end{array}$ \\
\hline Crítica & $\begin{array}{l}\text { Eapresentada a complexidade da relação ser humano-natureza. } \\
\text { Privilegia a dimensão política da questão ambiental e questiona o } \\
\text { modelo econômico vigente. Apresenta a necessidade do } \\
\text { fortalecimento da sociedade civil na busca coletiva de de } \\
\text { transformações sociais. }\end{array}$ \\
\hline
\end{tabular}

Nota. Fonte: Adaptado de Silva \& Campina (2011, p.33-34).

O Quadro 2 aborda as principais características de práticas de educação ambiental a partir de uma vertente Crítica da Educação Ambiental: 
Bio - grafía. Escritos sobre la Biología y su Enseñanza. ISSN 2027-1034

Edición Extraordinaria. p.p. 601 - 609

Memorias del IX Encuentro Nacional de Experiencias en Enseñanza de la Biología y la Educación Ambiental. IV Congreso Nacional de Investigación en Enseñanza de la Biología.

Quadro 2. Dimensão de Análise de Práticas Pedagógicas por Silva (2007)

\begin{tabular}{|l|l|}
\cline { 2 - 3 } \multicolumn{1}{c|}{} & \multicolumn{1}{c|}{ Caracterização da Educação Ambiental } \\
\hline Dimensão de Análise & \multicolumn{1}{c|}{ Concepção Crítica } \\
\hline \multirow{3}{*}{ Práticas pedagógicas } & - Práticas de atividades interdisciplinares \\
& - Eesolução de problemas com temas geradores \\
& - Estudo do meio \\
& - Role-play - tema controverso \\
\hline
\end{tabular}

A partir das considerações acerca dos aspectos presentes nas vertentes pedagógicas da EA destacadas por Silva (2007), devem ser levados em consideração os espaços em que estas atividades. Destacam-se os espaços formais de educação como a escola ou em espaços não formais de educação como museus e parques.

\section{PROCEDIMENTOS METODOLÓGICOS}

Esta pesquisa possui um caráter qualitativo e para a análise das atividades desenvolvidas ao longo desta etapa de intervenção em um espaço público, iremos adotar a Análise de Conteúdo (Bardin, 2011), objetivando estabelecer relações (limitações e aproximações) com a vertente pedagógica Crítica proposta por Silva (2007)

\subsection{Procedimentos metodológicos para o desenvolvimento das atividades}

No ano de 2015, por conta de uma parceria entre a uma escola pública da periferia da cidade de São Paulo uma Organização Não-governamental (ONG), foi implantado na escola um projeto de trabalho intitulado "Gincana Educativa", composto de diferentes atividades, dentre elas uma especifica em que deferia ser abordada aspectos da Educação Ambiental.

Por conta das várias atividades desenvolvidas na "Gincana Educativa" e da impossibilidade de todos os 20 professores participarem de todas as atividades, bem como a adesão voluntária dos professores e professoras nas atividades, 6 professores, sendo um professor da disciplina de geografia, duas professoras da disciplina de história, uma professora da disciplina de português, um professor da disciplina de Ciências e Biologia e um professor da disciplina de Educação Física.

A participação dos estudantes nas atividades obedeceu também ao critério de adesão, tendo em vista o caráter democrático do projeto e a dimensão e composição da escola, já que no ano de 2015 a escola em questão no turno matutino contava com 15 salas de aulas e por volta de 600 estudantes. 
Bio - grafía. Escritos sobre la Biología y su Enseñanza. ISSN 2027-1034

Edición Extraordinaria. p.p. 601 - 609

Memorias del IX Encuentro Nacional de Experiencias en Enseñanza de la Biología y la Educación Ambiental. IV Congreso Nacional de Investigación en Enseñanza de la Biología.

Para que pudessem ser identificados os estudantes que participariam da atividade de intervenção na praça foram reunidos os representantes dos alunos, sendo dois representantes de cada uma das 15 salas do período matutino. O professor de ciências conversou com os estudantes sobre a proposta da atividade e os estudantes ficaram responsáveis por divulgar as informações e identificar os estudantes que participariam da atividade.

Dois dias após a reunião com os representantes de sala foi elaborada uma lista com os estudantes do 9ㅜ ano do Ensino Fundamental e $1^{\circ}$ ano do Ensino Médio para que que pudéssemos solicitar as autorizações dos responsáveis dos estudantes, tendo em vista que iriamos realizar uma atividade fora do ambiente escolar. Nesta lista 60 alunos demonstraram o interesse de participar da atividade, sendo grade parte do 9o ano do Ensino Fundamental.

Diante da necessidade de se organizar uma atividade que abordasse aspectos da Educação Ambiental, e por meio de discussões entre professores e estudantes envolvidos no projeto desenvolvido em parceria com a ONG, foi apontado pelo professor de Geografia uma atividade de "Mapeamento dos problemas ambientais do bairro" com o objetivo de identificar os principais problemas ambientais do bairro, como por exemplo a poluição nos seus diferentes aspectos (visual, água, ar, sonora, etc.), de modo que os estudantes fizessem em grupo registros dos locais e problemas identificados.

Uma semana após ter solicitado o mapeamento dos problemas ambientais do bairro, os professores de geografia e ciências de posse das informações coletadas e dos diálogos com os estudantes identificaram um local de grande potencial para o desenvolvimento da atividade.

Diante da identificação do local para a prática da atividade, as professoras de História e de Português propuseram que os estudantes realizassem uma atividade de "Resgaste histórico da praça" por meio de narrativas orais, escritas ou fotográficas com o objetivo de identificar através da comunidade local quais os principais aspectos históricos e culturais que permearam aquele local e o que poderia justificar a situação atual de abandono daquela praça.

De posse de alguns registros feitos pelos estudantes e de uma reunião entre professores e estudantes para definirem uma atividade no local escolhido, houve uma mobilização no sentido de propor o "Dia de intervenção na praça", com o objetivo inicial de desenvolver uma atividade de limpeza para que fosse diminuído os impactos causados pela poluição no local e dado a este local uma melhor aparência. Entretanto ao longo das discussões foi sugerido também por alguns estudantes e da colaboração do professor de Educação Física no dia de intervenção também fosse realizada uma "Aula de expressão corporal e de dança" para o público participante da intervenção com o objetivo de dar um caráter de lazer a este espaço público.

Definida a estratégia de intervenção os pais dos estudantes foram notificados, por meio de um termo de autorização, quando a participação dos estudantes nesta atividade que iria ocorrer fora do ambiente escolar.

Para que pudessem avaliar os estudantes, os professores definiram que todas as atividades seriam utilizadas para a composição de uma avaliação de todo o 
Bio - grafía. Escritos sobre la Biología y su Enseñanza. ISSN 2027-1034

Edición Extraordinaria. p.p. 601 - 609

Memorias del IX Encuentro Nacional de Experiencias en Enseñanza de la Biología y la Educación Ambiental. IV Congreso Nacional de Investigación en Enseñanza de la Biología.

processo, e que os professores compartilhariam entre eles as notas das atividades desenvolvidas especificamente em sua disciplina.

\section{ANÁLISE DAS ATIVIDADES DESENVOLVIDAS E RELAÇÕES COM A VERTENTE PEDAGÓGICA CRÍTICA DA EA.}

Para que compreender as indagações propostas na pesquisa, recorremos a Análise de Conteúdo, por meio da proposta de Bardin (2011). Nosso percurso deveria se desenvolver pelas seguintes fases apontadas pela autora: pré-análise, exploração do material e o tratamento dos resultados, a inferência e a interpretação.

Na pré-análise buscou-se organizar, por meio descrição, as atividades que foram desenvolvidas por professores e estudantes, possibilitando compreender as diferentes etapas do seu processo de construção.

A etapa de exploração do material consistiu em submeter o entre o roteiro de atividades desenvolvidas (e que culminaram na intervenção do espaço público próximo do ambiente escolar) a uma análise mais aprofundada a partir do referencial teórico estabelecido, tendo como foco as categorias de analise as considerações feitas por Silva (2007) no que diz respeito a práticas pedagógicas da Vertente Crítica da EA.

Realizada a exploração do material, inicia-se a etapa de o tratamento dos resultados, a inferência e a interpretação, com vistas a estabelecer relações entre as categorias definidas a priori das práticas pedagógicas da vertente Crítica da EA proposta por Silva (2007) e as atividades desenvolvidas pela comunidade escolar (professores e estudante) de modo destacar aproximações e divergências. A partir disso identifica-se as seguintes relações:

\section{a) Prática de atividades interdisciplinares.}

Verifica-se nessa atividade um esforço no sentido de envolver professores de diferentes disciplinas (História, Geografia, Língua Portuguesa, Ciências, Biologia e Educação Física) no sentido de contribuir para o desenvolvimento da atividade, entretanto a atividade desenvolvida configura-se de "atividade multidisciplinar", no sentido de que cada professor buscou colaborar de maneira singular através do conhecimento específico da sua disciplina. No que refere, a contribuições dos professores de ciências, destaca-se sua importância ao abordar questões acerca da conservação dos ambientes e da compreensão acerca de aspectos como a poluição e dos impactos sobre a fauna e flora.

\section{b) Resolução de problemas com temas geradores.}

Um importante aspecto da atividade desenvolvida é a participação coletiva da comunidade escolar no sentido de identificar e definir, a partir de experiências pessoais e coletivas, quais os principais problemas ambientais do entorno da escola. Esta mobilização resultou na identificação de um tema gerador: "intervenção na praça" e na construção de uma atividade que contribuísse para a resolução de problemas presentes nela como a presença de resíduos e a utilização deste espaço para atividades de lazer.

Para que pudessem escolher um local para realizarem a intervenção foi necessário o apontamento de critérios para a escolha do espaço. Dentre os critérios destacam -se: 
Bio - grafía. Escritos sobre la Biología y su Enseñanza. ISSN 2027-1034

Edición Extraordinaria. p.p. 601 - 609

Memorias del IX Encuentro Nacional de Experiencias en Enseñanza de la Biología y la Educación Ambiental. IV Congreso Nacional de Investigación en Enseñanza de la Biología.

proximidade do local com a escola; presença ou potencialidade - para desenvolvimento- de várias espécies de seres vivos, e possibilitasse de desenvolvimento para atividades de lazer e convívio social.

\section{c) Exploração de potenciais ambientais/locais.}

O "dia de intervenção da praça" e a "aula de expressão corporal e dança" demonstraram para comunidade escolar o quanto a utilização de espaços públicos podem contribuir para a criação de ambientes de aprendizagem que não se resumem ao ambiente escolar. Contribuindo para que outros espaços do bairro tidos como abandonados possam ser vislumbrados como espaços onde ações coletivas podem ser construídas e que resultem no desenvolvimento de conscientização da importância da participação coletiva para a resolução de problemas locais, principalmente os de caráter ambiental.

\section{d) Estudo do meio.}

Ao propor que estudantes identifiquem no bairro problemas de ordem ambiental e busquem o resgate histórico de um espaço público do entorno da comunidade escolar, propiciou-se também um estudo do meio. Entretanto identifica-se que trabalho se caracterizar por ações de caráter individual por parte dos estudantes em realizar o estudo do meio.

As considerações realizadas sobre a participação dos estudantes, foram constituídas a partir das percepções dos professores, que ao interagirem com os estudantes na atividade de estudo do meio, puderam identificar a mudança de concepções que eles manifestaram. A constituição de um instrumento de análise de concepções pré e pós atividades poderia contribuir para identificar a evolução destas concepções.

\section{e) Role-play - tema controverso}

Identifica-se nesta atividade que não foram explorados a abordagem de questões controversas a aspectos como poluição, má utilização dos espaços públicos e a responsabilidade social e política da manutenção destes espaços. O que poderia contribuir para que todos envolvidos nesta atividade pudessem compreender de maneira mais crítica a importância das diversas personagens envolvidas na produção ou manutenção de um problema (no caso "o lixo na praça") e da importância de serem construídas propostas de ações para minimizar ou resolver o problema.

\section{CONSIDERAÇÕES FINAIS}

Os grandes centros urbanos, apesar de diversas questões problemáticas relacionadas a temática ambiental, possuem espaços que por serem de propriedade pública podem ser vislumbrados como de enorme potencial para que práticas de Educação Ambiental possam ser desenvolvidas, por meio de iniciativa de diferentes setores da sociedade, em especial por aquelas que são construídas dentro das comunidades escolar.

A escola configura-se com um importante local para que atividades de EA sejam desenvolvidas, entretanto há uma necessidade de que sejam compreendidas a partir de quais concepções se organizam estas atividades, para que os resultados 
Bio - grafía. Escritos sobre la Biología y su Enseñanza. ISSN 2027-1034

Edición Extraordinaria. p.p. 601 - 609

Memorias del IX Encuentro Nacional de Experiencias en Enseñanza de la Biología y la Educación Ambiental. IV Congreso Nacional de Investigación en Enseñanza de la Biología.

obtidos por elas possam ser compatíveis com os objetivos incialmente almejados e dos direcionamentos para determinados aspectos da formação dos professores, estudante e da comunidade envolvida.

Destaca-se a importância da participação dos professores em organizar atividades que contribuam para que estudantes possam ampliar e refletir sobre a potencialidade dos espaços públicos e da necessidade de ações que contribuam para a revitalização dos espaços urbanos.

Nesta pesquisa ao compreender a relação de uma atividade de EA desenvolvida por uma comunidade ambiente escolar e uma vertente Crítica da EA identificando que a prática de EA apresenta contribuições no que se diz respeito a organização dos estudantes para o mapeamento de problemas ambientais locais, definição de tema gerador, construção de propostas de ação e atividade de estudo do meio. Entretanto como limitações destacam-se a necessidade se organizar os trabalhos dos professores numa perspectiva interdisciplinar e da discussão de problemas locais e globais a partir de concepções mais abrangentes que destaquem aspectos controversas das questões abordadas.

Salienta-se que propostas de atividades de EA com a destacada nesta pesquisa podem resultar na identificação de problemas ambientais locais, discussão e delineamento de propostas de intervenção, retomada de espaços públicos para a atividades de lazer e formação de jovens que vislumbrem os espaços públicos como espaços coletivos e de grande potencial para o desenvolvimento de projetos ambientais.

\section{REFERÊNCIAS}

Almeida, L. F. R.; Bicudo, L. R. H. \& Borges, G. L. A. (2004). Educação Ambiental em praças públicas: professores e alunos descobrindo o ambiente urbano. Revista Ciência em Extensão, 1 (1), pp. 91-100.

Bardin, L. (2011). Análise de Conteúdo. Lisboa: Editora 70.

Bermúdez, G.; De Longhi, A. (2006). Propuesta curricular de hipótesis de progresión para conceptos estructurantes de ecología. Campo Abierto, v.25, pp.13-48.

Carvalho, I. C. (2002). O "Ambiental" como valor substantivo: uma reflexão sobre a identidade da educação ambiental. In: Sauvé, L.; Orellana \& I.; Sato, M (Orgs.), Textos escolhidos de educação ambiental: de uma América a outra (pp. 85-90). Montreal, Publications ERE - UQAM, Tomo I. 
Bio - grafía. Escritos sobre la Biología y su Enseñanza. ISSN 2027-1034

Edición Extraordinaria. p.p. 601 - 609

Memorias del IX Encuentro Nacional de Experiencias en Enseñanza de la Biología y la Educación Ambiental. IV Congreso Nacional de Investigación en Enseñanza de la Biología.

González Gaudiano, E. (2007). Educação ambiental para a biodiversidade: conceitos e práticas. In: Junqueira, V. \& Neiman, Z. (Orgs), Educação ambiental e conservação da biodiversidade: reflexões e experiências (pp. 3-11). Barueri: Manole.

Silva, R. L. F. (2007). O meio ambiente por trás da tela: estudo das concepções de Educação Ambiental dos filmes da TV Escola (Tese de Doutorado). Faculdade de Educação, Universidade de São Paulo, São Paulo, SP, Brasil.

Silva, R. L. F.; Campina, N. N. (2011). Concepções de educação ambiental na mídia e em práticas escolares: contribuições de uma tipologia. Pesquisa em Educação Ambiental, 6 (1), p. 29-46. 